\title{
Habitat type and schooling interactively determine refuge-seeking behavior in a coral reef fish throughout ontogeny
}

\author{
Chantal M. Huijbers ${ }^{1}$, Ivan Nagelkerken ${ }^{1,2, *}$, Laura L. Govers ${ }^{1}$, Madelon van de Kerk ${ }^{1}$, \\ Jeffrey J. Oldenburger ${ }^{1}$, Jan H. F. de Brouwer ${ }^{1}$
}

${ }^{1}$ Radboud University Nijmegen, Institute for Water and Wetland Research, Department of Animal Ecology and Ecophysiology, Mailbox No. 31, PO Box 9010, 6500 GL Nijmegen, The Netherlands

${ }^{2}$ Present address: Southern Seas Ecology Laboratories, Darling Building, School of Earth and Environmental Sciences, DX 650 418, The University of Adelaide, South Australia 5005, Australia

\begin{abstract}
Habitat selection by coral reef fish is influenced by a variety of biological and abiotic factors, but the relative importance of these factors is expected to change throughout ontogeny, especially for species that utilize different habitats during their life cycle. In this study, 2 in situ choice experiments were designed to test the individual as well as the interactive effects of habitat structure and schooling (with conspecifics or heterospecifics) on refuge-seeking behavior of a coral reef fish. The experiments were conducted for 3 size-classes of the common reef fish Haemulon flavolineatum, a species that shows multiple habitat shifts throughout its ontogeny. We tested the hypothesis that, due to the additive effects of schooling and structure in providing suitable refuge, fish would be more attracted to a microhabitat with conspecifics or heterospecifics than to a microhabitat or conspecifics alone. In the habitat-only experiment, early juveniles $(<3 \mathrm{~cm}$ fork length) showed no preference for any microhabitat structures, whereas larger fish preferred complex mangrove structure to seagrass, rubble, or coral. In the second experiment, which offered various combinations of habitat, including habitat with both conspecifics and heterospecifics, the preference for mangrove structure was completely replaced by attraction to conspecifics for all size-classes. Unexpectedly, the combination of conspecifics and habitat structure showed no additive effect. The results demonstrate that although $H$. flavolineatum makes multiple shifts in habitat throughout its life cycle, in the absence of other biological or environmental drivers preference for shelter habitat past the early post-settlement stage remains the same. The study further demonstrates the critical role of the presence of conspecifics in microhabitat choice, and provides a better understanding of the relative importance of these factors, whether in isolation or additively, in selection of refuge habitat by a reef fish.
\end{abstract}

KEY WORDS: Shelter - Schooling behavior $\cdot$ Visual cues $\cdot$ Habitat selection $\cdot$ Life cycle $\cdot$ Mangrove $\cdot$ Seagrass

Resale or republication not permitted without written consent of the publisher-

\section{INTRODUCTION}

Tropical coastal seascapes can contain a mosaic of different habitat types, such as coral reefs, seagrass beds, mangroves, sandy substrates and algal beds, which are ecologically connected through movement of organisms and flow of dissolved and particulate matter (Nagelkerken 2009). Dispersing animals may use a variety of these habitats consecutively during their ontogeny (Nagelkerken et al. 2000, Adams et al. 2006). Among coral reef fish species, several life-history strategies occur: (1) larvae can settle in the same habitat as adult conspecifics, whose presence likely indicates good habitat quality and protection for juvenile fish; (2) settlement among different habitats is indiscriminative, yet habitat-specific survival rates cause spatial differences in fish densities; (3) larval fishes can settle in markedly different habitats than 
those used by adult conspecifics and move to adult habitats in later life stages (McCormick \& Makey 1997, Adams et al. 2006, Pratchett et al. 2008). Ontogenetic habitat shifts, as exemplified by the third strategy, are often caused by changes in an animal's needs (Werner \& Gilliam 1984, Dahlgren \& Eggleston 2000). Animals often choose a particular habitat to minimize the ratio of mortality risk to growth rate, which characterizes the fitness of an animal (Werner \& Gilliam 1984). Factors that are closely related to mortality and growth, and that may thus directly or indirectly play a role in habitat selection, are food abundance (Cocheret de la Morinière et al. 2003, Pratchett et al. 2008), competition and predation (Rosenzweig 1991, Bonin et al. 2009, Grol et al. 2011a), habitat structure (Jenkins \& Wheatley 1998, Verweij et al. 2006a, Gullström et al. 2008), and the presence of conspecifics (Sweatman 1983, Lecchini et al. 2007a, Igulu et al. 2011).

Although larvae actively select their habitat during settlement, a 'good' habitat for settling larvae does not necessarily have to be a 'good' habitat for juveniles and adults as well (Lecchini et al. 2007b). Several experimental studies have found differences in habitat selection among different life stages of coral reef fish. Lecchini et al. (2007b) found that pre- and postmetamorphic stages of Thalassoma hardwicke chose different habitats in an ex situ aquarium experiment. Another aquarium experiment demonstrated that several species of the family Pomacentridae showed clear differences in habitat selection between preand post-settlers, while some species of the same family did not (Öhman et al. 1998). These laboratory results were consistent with the observed presence of these species in the field. Likewise, habitat selectivity in different life stages has been experimentally demonstrated in other marine species, like crabs (Lee et al. 2004, Webley et al. 2009) and temperate reef fish (McDermott \& Shima 2006). However, these studies have focused on habitat shifts in the early life stages of reef fish, the so-called 'transition phase' (Kaufman et al. 1992), while fish with an ontogenetic-habitat life style also display shifts among several habitat types during later life stages. In these stepwise postsettlement life-cycle migrations (Cocheret de la Morinière et al. 2002), juvenile fish move, for example, among different back-reef habitats like rubble areas, coral patches, mangroves and seagrass beds before eventually migrating back to the coral reef.

In previous in situ studies, habitat preference was mostly derived from distribution patterns based on visual censuses (e.g. McCormick \& Makey 1997, Nakamura et al. 2007). Laboratory ex situ experi- ments usually rebuilt microhabitats in choice chambers to investigate differences in habitat selectivity (e.g. Öhman et al. 1998, Bay et al. 2001, Lecchini et al. $2007 \mathrm{~b}$ ). In both types of studies, multiple factors, such as smell, structure and predation risk, which contribute to the decision-making process of animals, were often not excluded in the experimental design. Although this simulates the complexity of habitat choice in the real seascape, it makes it difficult to distinguish the role of individual factors in habitat selection.

In a complex seascape consisting of several habitat types, there is a large degree of variability in physical structures (Bell et al. 1991) - for example, leaves in seagrass beds, roots and pneumatophores in mangroves, and rocks and corals on reefs. Due to these differences it has been difficult to compare the importance of structural complexity among different habitats. Only a few studies have done so, and they have mostly addressed only 2 habitat types (Beck 1998, Jenkins \& Wheatley 1998, Nakamura et al. 2007, but see Grol et al. 2011b). In contrast, many studies have focused on animal responses towards structural variability within the same habitat type (e.g. coral reef: Chabanet et al. 1997; seagrass: Hyndes et al. 2003; mangroves: Cocheret de la Morinière et al. 2004). Fishes that settle and live in lagoonal environments can be confronted with a choice of various microhabitats on small spatial scales (i.e. meters). However, we understand very little about how the structure of different habitats contributes to habitat preference and utilization by fish.

Besides structure, another important factor that influences habitat selection is the presence of conspecifics or heterospecifics. Due to its accompanying increase in vigilance and defense against predators, social aggregation among fishes may enhance survival rates (Pitcher \& Parrish 1993, Orpwood et al. 2008). The effect of schooling behavior also differs among life stages of fish species (Macpherson 1998, Masuda \& Tsukamoto 1998). This behavior can be very important during the settlement stage when fish larvae are small and vulnerable. As fish grow, schooling may become less favorable due to increased competition for food (Hoare et al. 2000).

For the localization of habitats and conspecifics, fish can use several sensory mechanisms and environmental cues (Kingsford et al. 2002). Vision is believed to be an important sensory system in environments where water clarity is typically high, as on coral reefs (McCormick \& Manassa 2008, Huijbers et al. in press). Overall, the visual system of fish is well developed (Guthrie \& Muntz 1993), and previous 
studies have shown that fish can distinguish habitats (Lecchini et al. 2007b) and conspecifics (Brolund et al. 2003) by use of visual cues. However, little attention has been paid to the possible additive effects of habitat structure and presence of conspecifics in visual habitat choice by marine fishes.

In the present study, we tested visual preference by a common coral reef fish for structure of a suite of disparate habitat types that often co-occur in lagoonal environments, and for presence of conspecifics or heterospecifics with or without habitat structure. In order to suppress behaviors like searching for food or visually avoiding predators, all other biotic and environmental cues were excluded, making the driving behavioral mechanism refuge-seeking through structure and/or schooling. Two in situ multiplechoice experiments were designed to test (1) the visual attractiveness of 4 microhabitat refuges of different architecture (mangrove roots, seagrass shoots, corals and rubble), (2) the relative importance of schooling and microhabitat structure on refugeseeking behavior, and (3) the ontogenetic changes in preference for microhabitats or conspecifics/heterospecifics to a particular fish species. We hypothesized that (1) fish would show differences in the extent to which they are attracted to different types of microhabitat structure, (2) due to the additive effects of schooling and structure in providing suitable refuge (e.g. by minimizing predation risk), fish would be more attracted to a microhabitat with conspecifics or heterospecifics than to a 'bare' microhabitat or conspecifics alone, and (3) as a result of changing factors throughout ontogeny (e.g. a decrease in susceptibility to predation), the importance of schooling and structure would decrease with increasing body size.

\section{MATERIALS AND METHODS}

\section{Species and sampling}

The model species used in this study was the French grunt Haemulon flavolineatum, which is found in different habitats throughout its ontogeny. After a relatively short pelagic stage of approximately $14 \mathrm{~d}$ (McFarland et al. 1985), French grunts in Curaçao first settle on rubble zones in the mouths of inland bays before they move further into these bays, where they inhabit mangrove habitats and seagrass beds (Grol et al. 2011a); adults are mainly found on the coral reef. At approximately $5 \mathrm{~cm}$ they shift from diurnal plankton feeding to nocturnal benthic feed- ing (Verweij et al. 2006b). Juvenile grunts (>5 cm) exhibit schooling behavior during the day, when they are mostly inactive, and feed solitarily at night (Helfman et al. 1982). As grunts make use of several habitat types at different life-stages, and display both solitary and schooling behavior, it is a good model species for testing ontogenetic shifts in preference for different microhabitat structures and for conspecifics or heterospecifics.

Fish of the selected species were collected daily between August and December 2007 in the Spanish Water Bay and on the adjacent coral reef on the island of Curaçao, Netherlands Antilles $\left(12^{\circ} 04^{\prime} \mathrm{N}\right.$, $68^{\circ} 51^{\prime} \mathrm{W}$ ) by means of $\mathrm{v}$-shaped nets and fish traps. We collected fish of 3 different size-classes (all lengths measured as fork length) and from several habitats, resulting in 5 treatments: individuals (1) from 2 to $3 \mathrm{~cm}$ from the sand/rubble habitat at the mouth of the bay (early juveniles); (2) from 4 to $7 \mathrm{~cm}$ from the sand/rubble habitat at the mouth of the bay; (3) from 4 to $7 \mathrm{~cm}$ from the seagrass habitat within the bay; (4) from 10 to $15 \mathrm{~cm}$ from the seagrass habitat within the bay and (5) from 10 to $15 \mathrm{~cm}$ from the coral reef. Previous research had shown that fish $>12 \mathrm{~cm}$ from the reef were mature, while fish of the same size-class within the bay never reached maturity (Grol et al. 2011a). By selecting the same size-class from different habitats, we could determine whether choice behavior was affected by the residence habitat from which fish were taken, and was therefore caused by previous experience, or - if the same sizeclasses from different residence habitats showed the same preference for a specific habitat-whether there might be an intrinsic effect of habitat structure. After the fish had been collected, they were transported immediately over land to the laboratory, where they were housed overnight in aquaria, in small groups, with shelter and flowing seawater. They were used in our experiments the next day, and then released.

\section{Experimental set-up}

The importance of different structures and the presence of conspecifics/heterospecifics on shelterseeking behavior by Haemulon flavolineatum was studied in situ using experimental cages. The study area was a shallow sand flat in front of the laboratory at Piscadera Bay (see Huijbers et al. 2008). Cages were placed at a depth of $4.5 \mathrm{~m}$ on a sandy bottom at a distance of just $75 \mathrm{~m}$ from the holding tanks harboring the experimental fish, and $>50 \mathrm{~m}$ from any bay or 


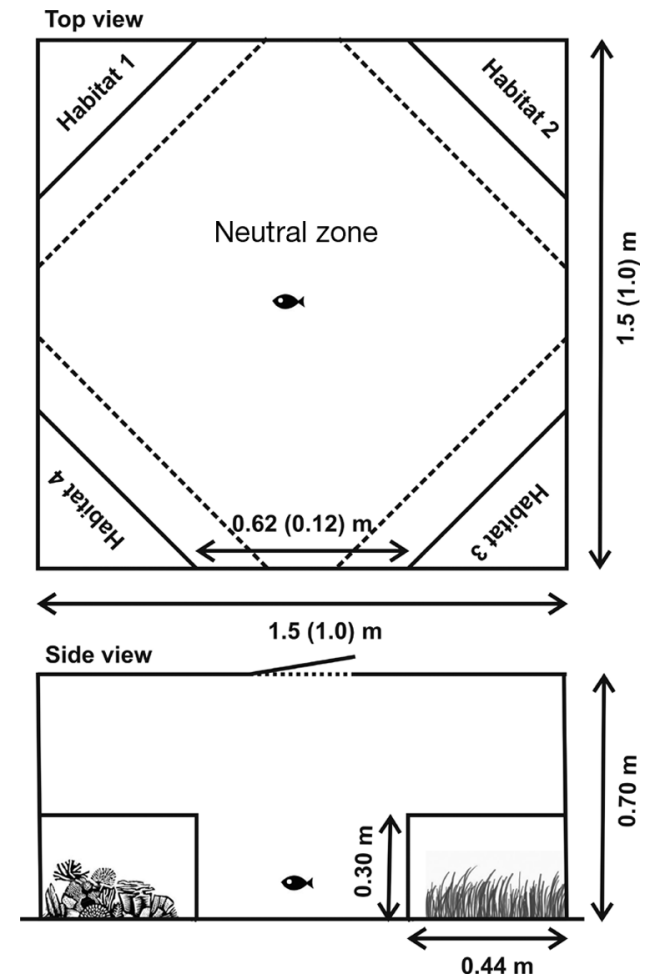

Fig. 1. Experimental design of underwater test cages, resting on a sandy bottom. In each corner a closed triangular box was placed with different microhabitat content (Expt 1), or (Expt 2) microhabitat alone, or a combination of microhabitat with French grunt conspecifics or heterospecifics. Middle of the cage is 'neutral' sandy zone. Dashed lines (top view): distance from box at which fish were considered to choose a given microhabitat; numbers: cage dimensions for fish $\geq 4 \mathrm{~cm}$, with altered dimensions for fish $\leq 3 \mathrm{~cm}$ in parentheses

reef habitats that might provide interfering cues to the fish. The cages $(1.5 \times 1.5 \times 0.7 \mathrm{~m}$ for fish $\geq 4 \mathrm{~cm}$; $1.0 \times 1.0 \times 0.7 \mathrm{~m}$ for fish $\leq 3 \mathrm{~cm}$ ) were constructed of iron rods $(\varnothing 8 \mathrm{~mm})$ and covered with $5 \mathrm{~mm}$ wire mesh, except for the cage bottom, which rested on the substratum. Into each corner of a cage, a closed triangular box was fitted (Fig. 1). These boxes, made of clear plexiglass (on the 2 sides, top and bottom) and glass (front pane facing the interior of the cage), fit tightly into each rectangular corner. The boxes were $44 \mathrm{~cm}$ long on each side by $30 \mathrm{~cm}$ high. To ensure that chemical cues from the content of the box would not influence the fishes' behavior, the boxes were kept tightly sealed during the observations. Thus, the observed preference of a fish for a particular microhabitat would be based only on visual cues. The cages further prevented interactive effects of other biological factors such as predation and competition by excluding other fishes. As the microhabitats were contained within the boxes, fishes were not able to search for food that was potentially associated with the structures. Hence, the driving behavioral mechanism was refuge-seeking (through structure and/or schooling). Between replicates the boxes were opened to provide a supply of fresh seawater to each box to keep the microhabitats alive. The use of 4 boxes in each corner created a 'neutral' sandy area in the middle of the cage where no visual cues of microhabitat structure were offered to the fish. All tests were run during daylight between 9:00 and 18:00 h.

In Expt 1, each box contained a different microhabitat in which Haemulon flavolineatum naturally occur during various life stages. Four habitat types were mimicked with pieces collected in the field. These were mangrove roots (Rhizophora mangle), seagrass shoots (Thalassia testudinum), rubble (small pieces of dead and broken coral) and living corals and sponges (e.g. Porites porites, Meandrina meandrites, Desmapsamma anchorata). Although the boxes were filled every few days with fresh material, the number of structures and height of each of the 4 microhabitats was kept the same, i.e. 8 mangrove roots, equal in length to the height of the box $(30 \mathrm{~cm})$, with spaces between the roots; 30 seagrass shoots from 10 to $15 \mathrm{~cm}$ high; 8 pieces of coral and sponge, each from 10 to $15 \mathrm{~cm}$ high; and 8 pieces of dead and broken coral (rubble), each from 10 to $15 \mathrm{~cm}$ high. In this experiment we tested preference for refuge habitat at different life stages.

In Expt 2, we tested the relative importance of microhabitat type and schooling (with conspecifics or heterospecifics) on refuge-seeking behavior throughout ontogeny. To this end, we filled 1 box with preferred microhabitat as revealed by Expt 1, 1 box with preferred microhabitat and 3 conspecifics, 1 box with preferred microhabitat and 3 heterospecifics, and 1 box with 3 conspecifics alone and no microhabitat. Conspecifics and heterospecifics were collected in the same habitat and size-classes as the fish tested. Selection of heterospecifics was based on their observed presence among schools of Haemulon flavolineatum in the field. For all size-classes $\geq 4 \mathrm{~cm}$, four-eye butterflyfish Chaetodon capistratus were used as heterospecifics. For fish $\leq 3 \mathrm{~cm}$, taken from the rubble habitat, juvenile ocean surgeonfish Acanthurus bahianus were used as heterospecifics.

In total, 1 small cage and 3 large cages were built to enable us to perform several replicate observations at the same time. These cages were placed a few meters apart, separated by polyehylene screens to prevent fishes from visually interacting and there- 
fore influencing each other's behavior. To rule out the effects of wave motion, currents and angle of sunlight, each cage was turned $90^{\circ}$ clockwise after every 2 replicates. In addition, the configuration of the boxes within the cage was changed after every 4 turns to rule out any treatment-order effects. With this set-up, 24 habitat configurations became possible, and each configuration was used to test from 2 to 3 individual fish per treatment for each of the 2 experiments. Mangrove habitat, for example, was placed 68, 75, 75 and 82 times in corners 1, 2, 3 and 4 of the cage, respectively, during the entire first experiment. Observations were made from a fixed position, while the cage and the microhabitats within the cage were re-configured as explained above. Thus, through this design, any potential observer effects were equal among microhabitat types and fish size-classes.

Each replicate observation was made on an individual fish, and habitat configuration was randomly assigned. To keep stress levels as low as possible, fishes were transported (in < $5 \mathrm{~min}$ ) from the lab holding tank to the underwater cage in a closed box with darkened sides. Each fish was put into a wire mesh cylinder, located in the centre of the cage, through an opening in the top of the cage (see Fig. 1). The fish was kept in the cylinder for $3 \mathrm{~min}$ to acclimate to its new environment. After $3 \mathrm{~min}$, the fish was released, the cylinder removed and the observation started. Upon release, fish were monitored for natural swimming behavior, and in no case was unnatural flight or movement observed. Instead, fish slowly investigated the habitats located behind the glass panes, apparently seeking an entrance to the contained microhabitat. Each fish was observed (using SCUBA equipment) for $15 \mathrm{~min}$ from behind the screens at a distance of $5 \mathrm{~m}$ from the cage, and its behavior in the cage was noted. Every between-microhabitat movement was recorded, from the moment a fish pointed its head toward the glassed-in microhabitat (within approx. $10 \mathrm{~cm}$ of the front pane) until it turned and swam away. It was always clear with which box they were associated during the course of the experiment. The between-habitat movements occurred at relatively low swimming speed (indicating lack of fleeing behavior), and fish could be easily followed while writing down time expenditure. This resulted in a budget for time spent at the various microhabitats for each fish. After the observations, fish were released at their site of capture. The experiment with microhabitats, as well as that with conspecifics and heterospecifics, was carried out with 43 to 61 individuals for each treatment, for a total of 534 fish tested.

\section{Statistical analysis}

Differences in choice of microhabitat structure or conspecifics/heterospecifics for each treatment of the 2 experiments were tested using a repeated-measures ANOVA, which accounts for the fact that the preference of 1 individual fish was tested for 4 different choices. Mauchly's test was used to test for sphericity of the data, and if this assumption was violated a Greenhouse-Geisser correction was used to produce a valid F-ratio. Preference for a specific microhabitat structure (Expt 1) or microhabitat with or without conspecifics or heterospecifics (Expt 2) was subsequently tested with a Bonferroni post hoc test. Among treatments, the difference in the percent time spent in the neutral zone, or in front of a particular box, was tested with a 1-way ANOVA followed by a Games-Howell post hoc test (Field 2005). An independent $t$-test was used to determine differences in time spent in the neutral area between Expts 1 and 2 for each treatment separately. For all tests a significance level of 0.05 was used.

\section{RESULTS}

\section{Expt 1: microhabitat type}

Among treatments, differences appeared in the percentage of time spent in the cage's neutral zone (Fig. 2). Early juveniles $(\leq 3 \mathrm{~cm}$ ) from the rubble habitat and large $(\geq 10 \mathrm{~cm})$ seagrass and reef fish spent significantly more time in the neutral zone than the 4 to $7 \mathrm{~cm}$ fish from the rubble and seagrass habitats (1-way ANOVA followed by Games-Howell post hoc

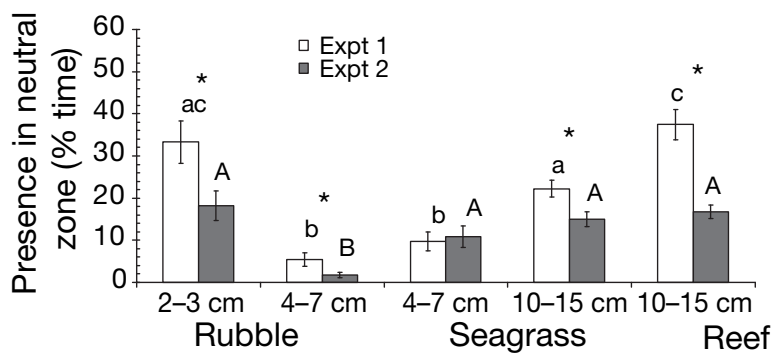

Fig. 2. Haemulon flavolineatum. Percentage of time (mean \pm SE) that fish from each treatment spent in the neutral zone. The $x$-axis shows size class of fish and habitat where captured. Lowercase letters: statistically significant differences among Expt 1 treatments; uppercase letters: significant differences among Expt 2 treatments (1-way ANOVA followed by Games-Howell post hoc test, $p<0.001$ for both experiments); asterisk: statistically significant differences $(\alpha=0.05)$ within treatment between Expts 1 and 2 (independent $t$-test) 

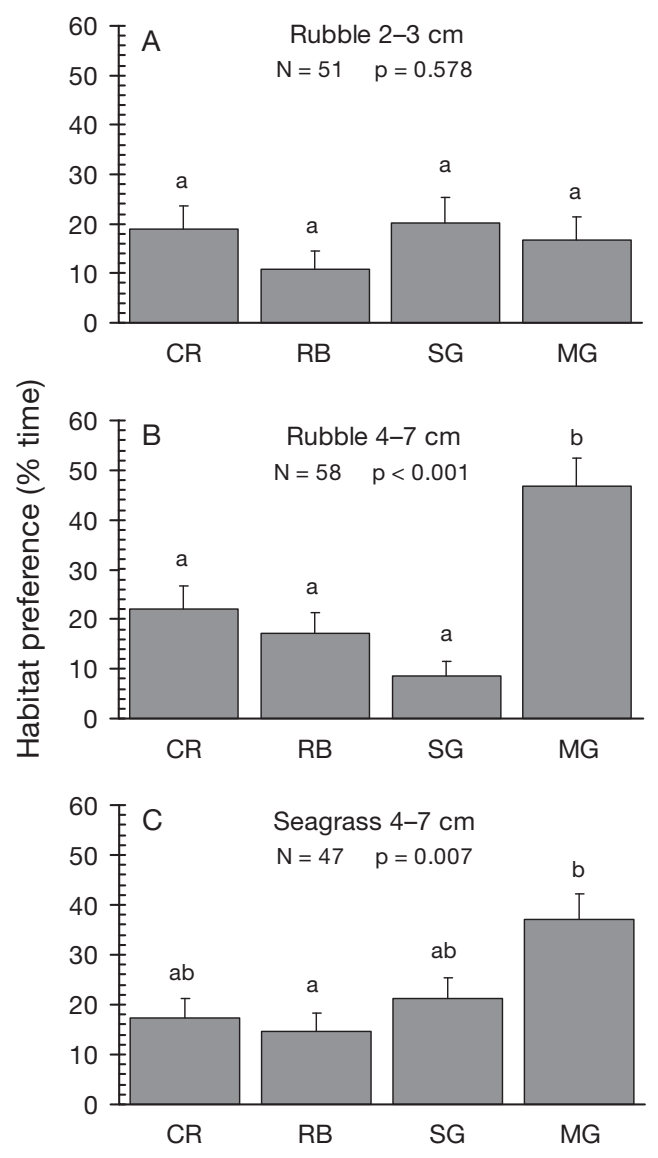

test, $\mathrm{p}<0.001)$. Large fish showed more active behavior in the experimental cages and, on average, visited more than 3 microhabitats (mean number of microhabitats visited: 10 to $15 \mathrm{~cm}$ seagrass fish: 3.7; 10 to $15 \mathrm{~cm}$ reef fish: 3.7 ), whereas small fish visited fewer than 3 microhabitats ( 2 to $3 \mathrm{~cm}$ rubble fish: 1.8 ; 4 to $7 \mathrm{~cm}$ rubble fish: $2.0 ; 4$ to $7 \mathrm{~cm}$ seagrass fish: 2.2 ). Of all fish $\geq 10 \mathrm{~cm}, 79 \%$ visited all 4 boxes harboring different microhabitats; of smaller fish $(\leq 7 \mathrm{~cm})$, only $9 \%$ did so. Because with every switch between microhabitats some time was spent in the neutral zone, the more frequent habitat switches by the larger fish increased the percentage of time spent in the neutral zone by that size-class. Results for very small fish differed from both these results. Fish $\leq 3 \mathrm{~cm}$ from the rubble did not switch often among microhabitats, yet $31 \%$ of these fish spent more than half their time in the neutral zone without appearing to choose any of the microhabitat structures, which accounts for the high percentage of neutral time in this treatment.

Despite the differences in time spent in the neutral area, fish from all treatments except the early juveniles $(\leq 3 \mathrm{~cm})$ preferred mangrove roots over other
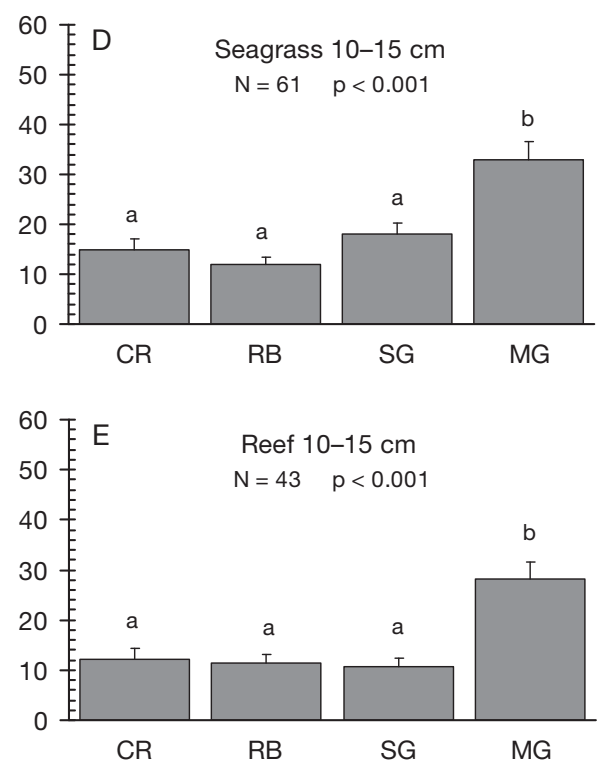

Fig. 3. Haemulon flavolineatum. Expt 1. Percentage of time $($ mean $+\mathrm{SE})$ that fish from each treatment $(\mathrm{A}-\mathrm{E})$ spent in front of each of the 4 boxes containing different microhabitat. CR: coral; RB: rubble; SG: seagrass; MG: mangrove. Collection habitat and size range of fish tested are shown as panel headings. p-values show results of repeatedmeasures ANOVA followed by Bonferroni post hoc test; if groups do not share the same lowercase letter, they differ significantly

microhabitats; among those other habitats (seagrass, coral, rubble) no preference was noted (Fig. 3). Early juveniles, for their part, showed no preference for any microhabitat (Fig. 3A).

\section{Expt 2: microhabitat vs. conspecifics/heterospecifics}

In Expt 2, the percentage of time spent in the neutral zone of the cage was significantly lower than for Expt 1 for each of the treatments, except for the 4 to $7 \mathrm{~cm}$ seagrass fish (Fig. 2). In Expt 2, therefore, a stronger overall attraction toward the experimental boxes was noted. Large $(\geq 10 \mathrm{~cm})$ fish again showed more active behavior and visited more microhabitats than did smaller fish (mean number of microhabitats visited: 2 to $3 \mathrm{~cm}$ rubble fish: $1.7 ; 4$ to $7 \mathrm{~cm}$ rubble fish: $1.3 ; 4$ to $7 \mathrm{~cm}$ seagrass fish: $1.7 ; 10$ to $15 \mathrm{~cm}$ seagrass fish: $3.4 ; 10$ to $15 \mathrm{~cm}$ reef fish: 3.5 ).

Fish showed a similar pattern from treatment to treatment and were most attracted to the 2 boxes containing conspecifics (Fig. 4). No significant difference was seen between boxes containing conspecifics alone or conspecifics with habitat. Boxes 

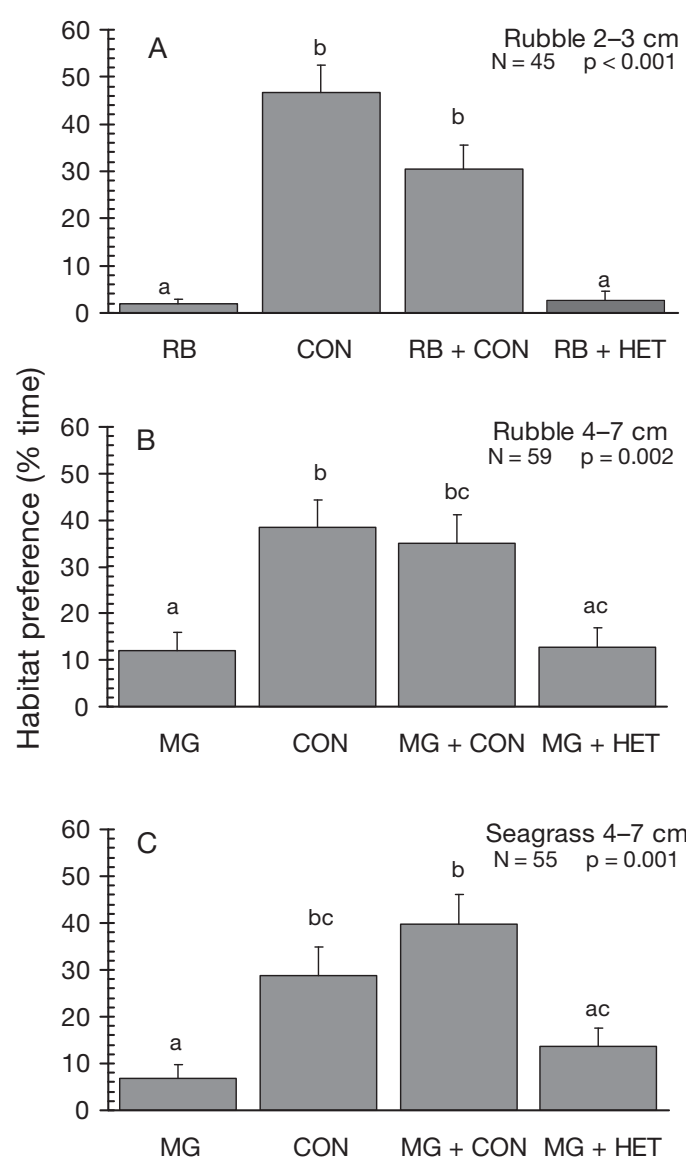

with solely habitat structure were significantly less preferred (Fig. 4). Likewise, preference for the heterospecifics/microhabitat combination was low, although we did note a trend of increasing preference for this combination with increasing fish size.

Notably, the preference for mangrove structure as displayed in Expt 1 was almost completely replaced in Expt 2 by attraction toward conspecifics (Fig. 5). Preference for conspecifics (with or without microhabitat) observed in Expt 2 did not differ significantly from preference for mangrove microhabitat observed in Expt 1 (1-way $\mathrm{ANOVA}_{i}$ for 4 to $7 \mathrm{~cm}$ rubble fish: $\mathrm{p}=$ 0.358 ; for 4 to $7 \mathrm{~cm}$ seagrass fish: $\mathrm{p}=0.387$; for 10 to $15 \mathrm{~cm}$ seagrass fish: $\mathrm{p}=0.431$; for 10 to $15 \mathrm{~cm}$ reef fish: $\mathrm{p}=0.900$ ). Preference for mangrove microhabitat alone was significantly lower in Expt 2 than in Expt 1 (independent $t$-test, $\mathrm{p}<0.001$ for all treatments).

\section{DISCUSSION}

In the present in situ microhabitat-choice experiment, fish of 2 different size classes caught in 3 different habitat types always preferred mangrove roots to seagrass, rubble or coral microhabitats. Only early
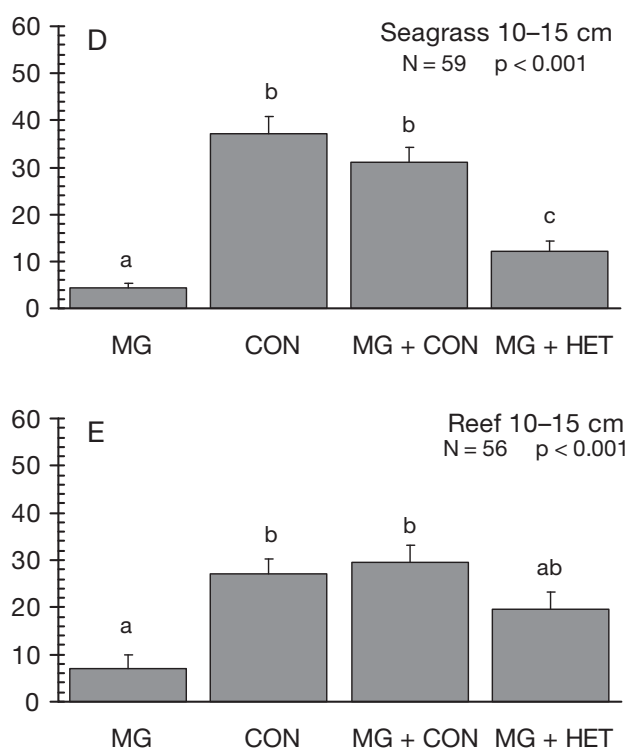

Fig. 4. Haemulon flavolineatum. Expt 2. Percentage of time (mean $+\mathrm{SE}$ ) that fish from each treatment (A-E) spent in front of each of the 4 boxes containing a different combination of microhabitat with or without conspecifics or heterospecifics. Preferred microhabitat from Expt 1 was used, viz. mangrove for all groups, except for early juveniles $(2-3 \mathrm{~cm})$, tested with rubble microhabitat. RB: rubble; MG: mangrove; CON: conspecifics; HET: heterospecifics. Collection habitat and size range of fish tested are shown as panel headings. p-values show results of repeatedmeasures ANOVA followed by Bonferroni post hoc test; if groups do not share the same lowercase letter, they differ significantly

juveniles $(\leq 3 \mathrm{~cm})$ did not discriminate between any of the offered microhabitats. As all cues, except vision, were excluded by using closed boxes in which the microhabitats were displayed, solely the visual attractiveness of habitat structures was tested. Because habitat provides refuge from predators, habitat structure plays a key role in the ecology of fishes (Hixon \& Beets 1993, Almany 2004). In an experimental setting

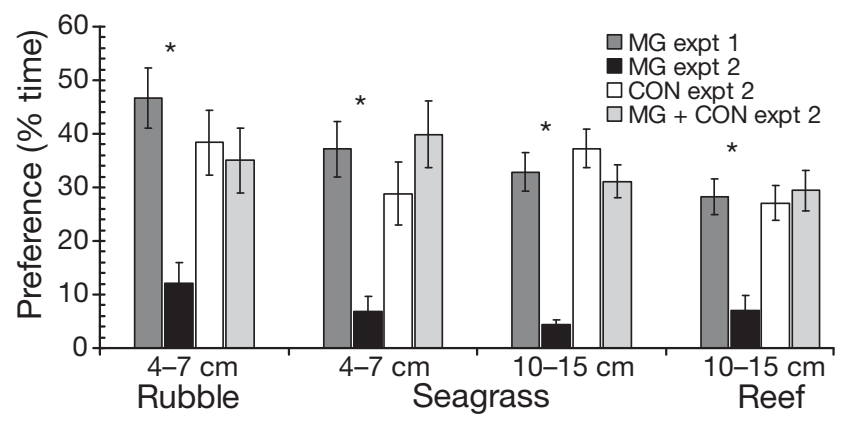

Fig. 5. Haemulon flavolineatum. Percentage of time (mean \pm $\mathrm{SE}$ ) fish $\geq 4 \mathrm{~cm}$, collected from 3 habitats, spent in front of boxes with mangrove habitat, and in front of boxes with conspecifics with or without mangrove habitat. MG: mangrove habitat; CON: conspecifics; asterisk: significant difference in preference for mangrove habitat, both experiments, tested with independent $t$-test 
where all common behaviors except refuge-seeking were repressed, mangrove structure, which probably provides superior shelter opportunities, was clearly preferred. This preference for refuge habitat was consistent in all but one treatment. The results show that fish were not simply attracted to the habitat in which they resided in situ, but were solely attracted to a single microhabitat type at all sizes $\geq 4 \mathrm{~cm}$.

The present study strengthens the argument that specific physical characteristics of a habitat are crucial determinants of microhabitat preference. The overruling preference for mangrove habitat is likely related to the combination of shade and high structural complexity that it offers (Laegdsgaard \& Johnson 2001, Cocheret de la Morinière et al. 2004, Verweij et al. 2006a, Nagelkerken et al. 2010). Nagelkerken \& Faunce (2007) found that besides mangrove-associated fish, other fish species are also attracted by mangrove structure, confirming the overall attractiveness of mangrove as shelter habitat. These authors suggested in a different paper that if mangroves occurred on coral reefs, they would be equally attractive to fish (Nagelkerken \& Faunce 2008). However, the preference for this habitat is contextdependent, being expressed by some species, including Haemulon flavolineatum, only towards standing mangrove roots (as in the current study), not hanging roots (Nagelkerken et al. 2010). Hence, other studies with $H$. flavolineatum have found preference for other (i.e. non-mangrove) microhabitat types in experiments using solely hanging mangrove microhabitat (Verweij et al. 2006a, Grol et al. 2011b). The preference for standing mangrove roots does not completely reflect the variable in situ distribution of this species (see review by Nagelkerken 2007). For free-ranging fish, it is likely that other factors like crowding and saturation of the mangrove habitat, competition or reproduction contribute to differential distribution among habitats (Adams \& Ebersole 2009).

In contrast to larger size-classes, early juveniles $(\leq 3 \mathrm{~cm})$ showed no preference for mangrove over other microhabitats. These fish spent a relatively high percentage of time in the neutral zone of the cage, which indicated to us a low attraction toward any habitat structure. Settlement-stage fish of different species display a range of behaviors in habitat selection, varying from consistent preference for one habitat type to no preference for any habitat type (Tupper \& Boutilier 1997, Öhman et al. 1998, Lecchini et al. 2007b). While other sensory cues, such as sound, olfaction or magnetism, operate over long distances (i.e. kilometers), it is vision that is mainly operative at short distances (i.e. meters; Kingsford et al. 2002).
During the early ontogeny of grunts the retinal morphology changes dramatically (McFarland \& Wahl 1996) and fish eyes develop rapidly in larvae (Myrberg \& Fuiman 2002). Because a smaller test cage was used for fish $\leq 3 \mathrm{~cm}$ to account for the relative distance to the habitats in relation to the size of the fish, we have excluded the possibility that our smallest individuals were unable to visually distinguish different microhabitat structures. Early post-settlement juveniles are small and vulnerable, making rapid growth and avoidance of predators of primary importance (Webster 2002, Almany 2003). Unlike individuals of approx. $>5 \mathrm{~cm}$ (Verweij et al. 2006b), these small fish are semi-pelagic diurnal feeders. Grol et al. (2011b) showed in a similar experiment, but one that provided open access to the microhabitats, that 3 to $4 \mathrm{~cm}$ individuals of Haemulon flavolineatum, a sizeclass that is diurnally active and thus not in shelter mode, avoided the confined space of mangrove shelter habitat during daytime. Factors like food availability and presence of predators were excluded in the present study, which may explain the fact that fish of $\leq 3 \mathrm{~cm}$ from the rubble habitat that were unable to feed in the enclosed microhabitats, and that were still relatively inexperienced, were not triggered to make a habitat choice in this experiment.

Our experiments clearly demonstrate a shift in microhabitat preference between the early juvenile stage $(\leq 3 \mathrm{~cm})$ and subsequent stages (from 4 to $15 \mathrm{~cm})$. Habitat preferences are often assumed to depend on early experience (Immelmann 1975, Davis \& Stamps 2004), as in salmon returning to their natal rivers based on olfactory imprinting during the early juvenile stage (Dittman \& Quinn 1996). As with most coral reef fish, the egg and larval stages of French grunts are pelagic before their settlement on a substratum (McFarland et al. 1985). Fish used for our experiments were caught on a substratum: rubble, seagrass or coral reef habitats. Experimental fish caught on seagrass beds in the bay, in the 4 to $7 \mathrm{~cm}$ size-class, may have developed their mangrove preference as a result of previous experience and social learning from conspecifics. However, fish of the same size-class caught in the rubble area also chose mangrove structure, even though they resided in a habitat away from nearby mangroves. It is unknown whether this affinity for some aspect of the mangrove habitat is inherited and only develops in later life stages, or if this behavior is learned during ontogeny.

Expt 2 showed that all size-classes from the different capture habitats equally preferred boxes with conspecifics regardless of the presence of microhabitat. For small fish among several species, the use 
of conspecifics to locate suitable settlement sites is common (Sweatman 1983, Tolimieri 1998, Lecchini et al. 2007a). As fish grow larger, schooling behavior is often a trade-off between the costs and benefits of being a group member (Hoare et al. 2000). The present study shows that the advantages of social group formation can remain important throughout the life cycle of a demersal reef fish species. The significant preference that we observed for conspecifics over heterospecifics in all size classes matches the observations of schooling behavior of French grunts in the field (Ogden \& Ehrlich 1977). Interest (among individuals of our test species) in heterospecifics increases to a certain degree with increasing fish size, which may suggest that fishes gradually become less particular in the choice of species with which they form schools.

Combined visual cues of microhabitat structure and presence of conspecifics evoked no stronger response than did visual cues of conspecifics alone, clearly indicating a lack of additivity of habitat to conspecific presence. Interest in mangrove habitat alone decreased significantly in Expt 2 over Expt 1, and was completely replaced by attraction to conspecifics. This reveals that, for some demersal fish species (in absence of visible predators), schooling may be preferred to seeking out a particular habitat structure as a refuge-seeking behavior. In the field, however, Haemulon flavolineatum is found in schools around structurally complex habitat (C. M. Huijbers \& I. Nagelkerken pers. obs.) and the species does not school on unstructured sandy substratum, a behavior probably driven by visual awareness of predators.

Both shelter-seeking in complex habitat and schooling behavior serve as important anti-predation strategies in fish (Pitcher \& Parrish 1993, Hoare et al. 2000). Few studies could be found that explicitly examined the relative importance of these 2 antipredation strategies. One study found that European minnows formed larger shoals in simple habitats than in complex habitats (Orpwood et al. 2008). They concluded that schooling behavior was mainly observed when shelter opportunities provided by physical habitat structure were insufficient, but our study shows that schooling occurs even within dark, complex habitat. Another study that investigated the interaction between sheltering and group behavior found that 2 reef fish species were both strongly associated with structurally complex finger coral, and that schooling behavior occurred mainly at short distances from this substratum (DeMartini \& Anderson 2007). Gardiner \& Jones (2010) and Igulu et al. (2011) furthermore found that the strength of specific habitat preferences can be modified by the presence of conspecifics, and that conspecifics can render less preferred habitats more attractive. Our results show that, for Haemulon flavolineatum, schooling behavior can overrule the shelter attraction of habitat structure when the opportunities for other behavioral mechanisms are curtailed.

Enclosing fish in experimental cages may introduce undesirable artifacts, such as increased stress levels, into the experiment. In our experiments, fish did not show high stress levels. They did not swim rapidly to a random box immediately upon release, nor did they seek shelter in the corners of the cage. They rather calmly visited multiple boxes. By using a closed and controlled test environment, we ensured that only the visual attraction to microhabitat structure and conspecifics or heterospecifics was measured. This might not reflect actual habitat choice of fish in situ, where a number of factors must be taken into account, but it does provide essential information about the importance of some of those factors. All our experiments were carried out during the day, but French grunts larger than $5 \mathrm{~cm}$ are nocturnally active (Verweij et al. 2006b), and would probably have shown a different choice behavior if they were tested during nighttime. However, the focus of our study was to investigate the role of habitat, interactively with schooling, as a refuge-seeking behavior, and therefore all treatments except for fish $\leq 3 \mathrm{~cm}$ were suitable, as they reflected life stages in which fish are largely in shelter mode during daytime. Nighttime experiments, on the other hand, would probably have yielded information on the role of habitat in feeding behavior. It should be noted, however, that, because the maximum distance from any microhabitat was $<1 \mathrm{~m}$, only a scale-dependent component of the habitat selection process could be studied.

\section{CONCLUSIONS}

When habitat structure was offered in isolation, fish $\geq 4 \mathrm{~cm}$ showed a preference, based on visual cues alone, for mangrove microhabitat. However, the presence of conspecifics, but not of heterospecifics, appears to overrule this factor during all life stages. To our knowledge, this is the first study in which the preference for the structure of 4 very different tropical microhabitats, and the interaction of microhabitat structure and presence of conspecifics or heterospecifics, has been tested simultaneously using several size-classes of fish typical of the ontogeny of a reef fish. This provides a better understanding of the role of these factors, whether in isolation or additively, in the refuge-seeking behavior of a reef fish. 
Acknowledgements. This project was supported by the Netherlands Organization for Scientific Research (NWO) through a VIDI grant to I.N. We thank all staff and personnel of the CARMABI Foundation on Curaçao for their hospitality and provision of research materials. This is Centre for Wetland Ecology publication no. 541.

\section{LITERATURE CITED}

Adams AJ, Ebersole JP (2009) Mechanisms affecting recruitment patterns of fish and decapods in tropical coastal ecosystems. In: Nagelkerken I (ed) Ecological connectivity among tropical coastal ecosystems. Springer, Dordrecht, p 185-228

- Adams AJ, Dahlgren CP, Kellison GT, Kendall MS and others (2006) Nursery function of tropical back-reef systems. Mar Ecol Prog Ser 318:287-301

Almany GR (2003) Priority effects in coral reef fish communities. Ecology 84:1920-1935

> Almany GR (2004) Does increased habitat complexity reduce predation and competition in coral reef fish assemblages? Oikos 106:275-284

> Bay L, Jones GP, McCormick MI (2001) Habitat selection and aggression as determinants of spatial segregation among damselfish on a coral reef. Coral Reefs 20:289298

> Beck MW (1998) Comparison of the measurement and effects of habitat structure on gastropods in rocky intertidal and mangrove habitats. Mar Ecol Prog Ser 169:165178

Bell SS, McCoy ED, Mushinsky HR (eds) (1991) Habitat structure: the physical arrangement of objects in space. Chapman \& Hall, London

Bonin MC, Srinivasan M, Almany GR, Jones GP (2009) Interactive effects of interspecific competition and microhabitat on early post-settlement survival in a coral reef fish. Coral Reefs 28:265-274

> Brolund TM, Nielsen LE, Arvedlund M (2003) Do juvenile Amphiprion ocellaris (Pisces: Pomacentridae) recognize conspecifics by chemical or visual cues? J Mar Biol Assoc UK 83:1127-1136

> Chabanet P, Ralambondrainy H, Amanieu M, Faure G, Galzin R (1997) Relationships between coral reef substrata and fish. Coral Reefs 16:93-102

> Cocheret de la Morinière E, Pollux BJA, Nagelkerken I, van der Velde G (2002) Post-settlement life cycle migration patterns and habitat preference of coral reef fish that use seagrass and mangrove habitats as nurseries. Estuar Coast Shelf Sci 55:309-321

> Cocheret de la Morinière E, Pollux BJA, Nagelkerken I, van der Velde G (2003) Diet shifts of Caribbean grunts (Haemulidae) and snappers (Lutjanidae) and the relation with nursery-to-coral reef migrations. Estuar Coast Shelf Sci 57:1079-1089

> Cocheret de la Morinière E, Nagelkerken I, van der Meij H, van der Velde G (2004) What attracts juvenile coral reef fish to mangroves: habitat complexity or shade? Mar Biol 144:139-145

Dahlgren CP, Eggleston DB (2000) Ecological processes underlying ontogenetic habitat shifts in a coral reef fish. Ecology 81:2227-2240

> Davis JM, Stamps JA (2004) The effect of natal experience on habitat preferences. Trends Ecol Evol 19:411-416

DeMartini EE, Anderson TW (2007) Habitat associations and aggregation of recruit fishes on Hawai'ian coral reefs. Bull Mar Sci 81:139-152

- Dittman A, Quinn TP (1996) Homing in Pacific salmon: mechanisms and ecological basis. J Exp Biol 199:83-91

Field A (2005) Discovering statistics using SPSS, 2nd edn. SAGE Publications, London

> Gardiner NM, Jones GP (2010) Synergistic effects of habitat preference and gregarious behaviour on habitat use in coral reef cardinalfish. Coral Reefs 29:845-856

> Grol MGG, Nagelkerken I, Rypel AL, Layman CA (2011a) Simple ecological trade-offs give rise to emergent crossecosystem distributions of a coral reef fish. Oecologia 165:79-88

> Grol MGG, Nagelkerken I, Bosch N, Meesters EH (2011b) Preference of early juveniles of a coral reef fish for distinct lagoonal microhabitats is not related to common measures of structural complexity. Mar Ecol Prog Ser 432:221-233

Gullström M, Bodin M, Nilsson PG, Öhman MC (2008) Seagrass structural complexity and landscape configuration as determinants of tropical fish assemblage composition. Mar Ecol Prog Ser 363:241-255

Guthrie DM, Muntz WRA (1993) Role of vision in fish behavior. In: Pitcher TJ (ed) Behavior of teleost fishes, 2nd edn. Chapman \& Hall, London, p 89-121

Helfman GS, Meyer JL, McFarland WN (1982) The ontogeny of twilight migration patterns in grunts (Pisces: Haemulidae). Anim Behav 30:317-326

Hixon MA, Beets JP (1993) Predation, prey refuges and the structure of coral-reef fish assemblages. Ecol Monogr 63: 77-101

Hoare DJ, Krause J, Peuhkuri N, Godin JGJ (2000) Body size and shoaling in fish. J Fish Biol 57:1351-1366

Huijbers CM, Mollee EM, Nagelkerken I (2008) Post-larval French grunts (Haemulon flavolineatum) distinguish between seagrass, mangrove and coral reef water: implications for recognition of potential nursery habitats. J Exp Mar Biol Ecol 357:134-139

Huijbers CM, Nagelkerken I, Lössbroek PAC, Schulten IE, Siegenthaler A, Holderied MW, Simpson SD (in press) A test of the senses: fish select novel habitats by responding to multiple cues. Ecology

Hyndes GA, Kendrick AJ, MacArthur LD, Stewart E (2003) Differences in the species- and size-composition of fish assemblages in three distinct seagrass habitats with differing plant and meadow structure. Mar Biol 142: 1195-1206

Igulu MM, Nagelkerken I, Fraaije R, van Hintum R, Ligtenberg H, Mgaya YD (2011) The potential role of visual cues for microhabitat selection during the early life phase of a coral reef fish (Lutjanus fulviflamma). J Exp Mar Biol Ecol 401:118-125

> Immelmann K (1975) Ecological significance of imprinting and early learning. Annu Rev Ecol Syst 6:15-37

> Jenkins GP, Wheatley MJ (1998) The influence of habitat structure on nearshore fish assemblages in a southern Australian embayment: comparison of shallow seagrass, reef-algal and unvegetated sand habitats, with emphasis on their importance to recruitment. J Exp Mar Biol Ecol 221:147-172

> Kaufman L, Ebersole J, Beets J, McIvor CC (1992) A key phase in the recruitment dynamics of coral reef fishes: post-settlement transition. Environ Biol Fishes 34: 109-118

Kingsford MJ, Leis JM, Shanks A, Lindeman KC, Morgan 
SG, Pineda J (2002) Sensory environments, larval abilities and local self-recruitment. Bull Mar Sci 70:309-340

- Laegdsgaard P, Johnson C (2001) Why do juvenile fish utilise mangrove habitats? J Exp Mar Biol Ecol 257: $229-253$

Lecchini D, Planes S, Galzin R (2007a) The influence of habitat characteristics and conspecifics on attraction and survival of coral reef fish juveniles. J Exp Mar Biol Ecol 341: 85-90

> Lecchini D, Osenberg CW, Shima JS, Mary CM, Galzin R (2007b) Ontogenetic changes in habitat selection during settlement in a coral reef fish: ecological determinants and sensory mechanisms. Coral Reefs 26:423-432

> Lee JT, Widdows J, Jones MB, Coleman RA (2004) Settlement of megalopae and early juveniles of the velvet swimming crab Necora puber (Decapoda: Portunidae) in flow conditions. Mar Ecol Prog Ser 272:191-202

> Macpherson E (1998) Ontogenetic shifts in habitat use and aggregation in juvenile sparid fishes. J Exp Mar Biol Ecol 220:127-150

Masuda R, Tsukamoto K (1998) The ontogeny of schooling behaviour in the striped jack. J Fish Biol 52:483-493

> McCormick MI, Makey LJ (1997) Post-settlement transition in coral reef fishes: overlooked complexity in niche shifts. Mar Ecol Prog Ser 153:247-257

McCormick MI, Manassa R (2008) Predation risk assessment by olfactory and visual cues in a coral reef fish. Coral Reefs 27:105-113

McDermott CJ, Shima JS (2006) Ontogenetic shifts in microhabitat preference of the temperate reef fish Forsterygion lapillum: implications for population limitation. Mar Ecol Prog Ser 320:259-266

> McFarland WN, Wahl CM (1996) Visual constraints on migration behavior of juvenile French grunts. Environ Biol Fishes 46:109-122

McFarland WN, Brothers EB, Ogden JC, Shulman MJ, Bermingham EL, Kotchian-prentiss NM (1985) Recruitment patterns in young French grunts, Haemulon flavolineatum (family Haemulidae), at St. Croix, Virgin Islands. Fish Bull 83:413-426

Myrberg AA, Fuiman LA (2002) The sensory world of coral reef fishes. In: Sale PF (ed) Coral reef fishes: dynamics and diversity in a complex ecosystem. Elsevier Science, San Diego, CA, p 123-148

Nagelkerken I (2007) Are non-estuarine mangroves connected to coral reefs through fish migration? Bull Mar Sci 80:595-607

Nagelkerken I (2009) (ed) Ecological connectivity among tropical coastal ecosystems. Springer Science and Business Media, Dordrecht

> Nagelkerken I, Faunce CH (2007) Colonisation of artificial mangroves by reef fishes in a marine seascape. Estuar Coast Shelf Sci 75:417-422

Nagelkerken I, Faunce CH (2008) What makes mangroves attractive to fish? Use of artificial units to test the influence of water depth, cross-shelf location, and presence of root structure. Estuar Coast Shelf Sci 79:559-565

Nagelkerken I, Dorenbosch M, Verberk WCEP, Cocheret de la Morinière E, van der Velde G (2000) Importance of shallow-water biotopes of a Caribbean bay for juvenile coral reef fishes: patterns in biotope association, commu-

Editorial responsibility: Thomas Minello, Galveston, Texas, USA nity structure and spatial distribution. Mar Ecol Prog Ser 202:175-192

Nagelkerken I, De Schryver AM, Verweij MC, DahdouhGuebas F, Van der Velde G, Koedam N (2010) Differences in root architecture influence attraction of fishes to mangroves: a field experiment mimicking roots of different length, orientation, and complexity. J Exp Mar Biol Ecol 396:27-34

> Nakamura Y, Kawasaki H, Sano M (2007) Experimental analysis of recruitment patterns of coral reef fishes in seagrass beds: effects of substrate type, shape, and rigidity. Estuar Coast Shelf Sci 71:559-568

> Ogden JC, Ehrlich PR (1977) The behavior of heterotypic resting schools of juvenile grunts (Pomadasyidae). Mar Biol 42:273-280

Öhman MC, Munday PL, Jones GP, Caley MJ (1998) Settlement strategies and distribution patterns of coral-reef fishes. J Exp Mar Biol Ecol 225:219-238

Orpwood JE, Magurran AE, Armstrong JD, Griffiths SW (2008) Minnows and the selfish herd: effects of predation risk on shoaling behaviour are dependent on habitat complexity. Anim Behav 76:143-152

Pitcher TJ, Parrish JK (1993) Functions of shoaling behaviour in teleosts,. In: Pitcher TJ (ed) Behaviour of teleost fishes, 2nd edn. Chapman \& Hall, London, p 363-439

Pratchett MS, Berumen ML, Marnane MJ, Eagle JV, Pratchett DJ (2008) Habitat associations of juvenile versus adult butterflyfishes. Coral Reefs 27:541-551

Rosenzweig ML (1991) Habitat selection and population interactions: the search for mechanism. Am Nat 137: S5-S28

> Sweatman HPA (1983) Influence of conspecifics on choice of settlement sites by larvae of two Pomacentrid fishes (Dascyllus aruanus and D. reticulatus) on coral reefs. Mar Biol 75:225-229

Tolimieri N (1998) Effects of substrata, resident conspecifics and damselfish on the settlement and recruitment of the stoplight parrotfish, Sparisoma viride. Environ Biol Fishes 53:393-404

> Tupper M, Boutilier RG (1997) Effects of habitat on settlement, growth, predation risk and survival of a temperate reef fish. Mar Ecol Prog Ser 151:225-236

> Verweij MC, Nagelkerken I, de Graaff D, Peeters M, Bakker EJ, van der Velde G (2006a) Structure, food and shade attract juvenile coral reef fish to mangrove and seagrass habitats: a field experiment. Mar Ecol Prog Ser 306: 257-268

> Verweij MC, Nagelkerken I, Wartenbergh SLJ, Pen IR, van der Velde G (2006b) Caribbean mangroves and seagrass beds as daytime feeding habitats for juvenile French grunts, Haemulon flavolineatum. Mar Biol 149:1291-1299

Webley JAC, Connolly RM, Young RA (2009) Habitat selectivity of megalopae and juvenile mud crabs (Scylla serrata): implications for recruitment mechanism. Mar Biol 156:891-899

- Webster MS (2002) Role of predators in the early post-settlement demography of coral-reef fishes. Oecologia 131: $52-60$

Werner EE, Gilliam JF (1984) The ontogenetic niche and species interactions in size-structured populations. Annu Rev Ecol Syst 15:393-425

Submitted: November 10, 2010; Accepted: June 17, 2011 Proofs received from author(s): August 29, 2011 